\title{
Research on the Training Path of Professional Core Literacy Matching Ability of Private Universities under the Background of New Liberal Arts
}

\author{
Chenmin Ni \\ Zhejiang Yuexiu University, Shaoxing, China \\ Email: cmni@163.com
}

How to cite this paper: Ni, C. M. (2021) Research on the Training Path of Professional Core Literacy Matching Ability of Private Universities under the Background of New Liberal Arts. Open Journal of Social Sciences, 9, 163-172.

https://doi.org/10.4236/jss.2021.910012

Received: September 3, 2021

Accepted: October 18, 2021

Published: October 21, 2021

Copyright (c) 2021 by author(s) and Scientific Research Publishing Inc. This work is licensed under the Creative Commons Attribution International License (CC BY 4.0).

http://creativecommons.org/licenses/by/4.0/

(c) (†) Open Access

\begin{abstract}
Guided by the core theory of comprehensively launching the new liberal arts construction conference, aiming at cultivating applied and compound talents, based on the perspective of OBE teaching theory, integrating the characteristics of our own university, taking the characteristics of economic statistics as an example, this paper constructs the core literacy index matching with the core literacy of Chinese students' development, and studies the matching curriculum and education path. Reconstruct the design in the aspects of basic knowledge, professional quality, application of statistical tools, practical innovation and cross-cultural cooperation, form a training path framework, enable students to form the ability to match the professional core quality in the new liberal arts era, then the fuzzy comprehensive evaluation matrix is further constructed, and the index evaluation system based on the development of core literacy is established. Finally, the research results are discussed.
\end{abstract}

\section{Keywords}

Professional Core Quality, Economic Statistics, OBE, Training Path, Fuzzy Comprehensive Evaluation

\section{Introduction}

Core literacy refers to the necessary character and key ability that students should have and can meet the needs of lifelong development and social development. It is also called "21st century literacy" or "21st century skills" abroad. The research started in 1997 when the organization for economic cooperation 
and development (OECD) launched the "deseco" program in the United States. The three core qualities finally established are the ability to use tools interactively, interact effectively in heterogeneous groups and act independently. In March 2001, the EU established the "education and training 2010 work project", which formed eight core qualities of the EU around 2010, namely "mother tongue communication, foreign language communication, mathematics literacy and basic science and technology literacy, digital literacy, learning to learn, social and civic literacy, initiative and entrepreneurial awareness, cultural awareness and expression". Scholars such as Vogt of the Netherlands, Levi and Monet of the United States further simplified the international core literacy into four qualities, namely cooperation, communication, creativity and critical thinking, namely the famous "4C's in the 21st century" (Voogt \& Robin, 2012). In 2020, Chinese scholars added "cooperative nutrition" to build the " $5 \mathrm{C}$ model of core literacy in the 21st century" (Xu et al., 2020). The Ministry of Education of the People's Republic of China clearly put forward "research and formulate the core literacy system for students' development" in the Document No. 2 [2014] 4 of the Education Foundation of the People's Republic of China, and took cultivating students' core literacy as the key path to implement the fundamental task of building morality and cultivating people. In September 2016, the overall framework of Chinese students' development core literacy was released, namely, cultural foundation, independent development and social participation. It has constructed six qualities: humanistic heritage, scientific spirit, learning to learn, healthy life, responsibility and practical innovation, which are detailed into 18 key points. From 2016 to 2019, Zhang Hua of Hangzhou Normal University, Xin Tao of Beijing Normal University and Kong Fanzhe of Northeast Normal University demonstrated the connotation, cultivation and evaluation of core literacy by age in their papers (Zhang, 2016; Xin et al., 2016); they pointed out that core literacy can be cultivated and developed. Subsequently, educators analyzed college students' ideological and political core literacy, art core literacy, core literacy and sound personality cultivation, and further clarified the importance of the core literacy framework for college students' ability cultivation (Wang \& Jin, 2019; Zeng, 2019; Fan, 2020).

In November 2020, a conference on the construction of new liberal arts under the guidance of the Department of higher education of the Ministry of education of China was held in Shandong University. The Declaration on the construction of new liberal arts issued by the conference and the speeches of scholars such as the director of education and the presidents of Universities pointed out that the liberal arts education in Colleges and universities should be based on "Building Morality and cultivating people, family and country feelings, cultural literacy, international vision Taking "cross integration" as the goal and "needs, objectives and characteristics" as the three starting points, promote the cross integration of disciplines, optimize the talent training objectives, and cultivate applied and compound liberal arts talents to meet the requirements of the new era (Duan \& Cui, 2020). So the talent training needs under the background of the new liberal 
arts are similar to the focus of Chinese students' development core literacy. The Ministry of education of China defined the discipline core literacy and academic quality standards in the discipline standards of ordinary high schools in 2018. At the university stage, due to the professional segmentation, the core quality of each major is not clarified. Each major in each university needs to adjust itself according to the characteristics of its students and market demand, combined with the requirements of the Ministry of education.

Private colleges and universities are an important part of China's education. As of June 2021, there are more than 700 private undergraduate colleges and universities, which is an important supplement to public education. Compared with public colleges and universities, private colleges and universities have strong flexibility in school running mechanism and talent training mode. They can timely adjust training objectives and talent training programs according to market demand, so as to improve teaching quality and students' market competitiveness and better play the school brand. In recent years, with the transfer of independent colleges and the continuous enrollment expansion of public colleges, the development competitiveness of private colleges and universities has been increasing. How to match the professional setting and construction of various disciplines in various colleges and universities with the overall framework of Chinese students' development of core literacy, so as to make students have the ability to match the core literacy while developing their own characteristics and professional characteristics, And establishing a reasonable evaluation system is a hot issue for educators.

\section{Construction of the Training Path of College Students' Professional Core Literacy Matching Ability}

\subsection{OBE Education Theory (Liu et al., 2020)}

OBE is the abbreviation of outcome based education. At present, OBE has become the mainstream of education reform in Britain, America, Australia, Cana$\mathrm{da}$ and other countries. It reversely guides the formulation of teaching design and teaching implementation objectives with the learning results obtained by students after learning, and cooperates with the diversified and flexible personalized learning requirements to enable students to achieve self-realization through the learning process, Then feedback the results to improve the original curriculum design and curriculum teaching. To implement the OBE education concept, the focus is to grasp five points for path design. The first is the goal. What should students learn and master? Second, why should we learn these contents? The third is the process, how to help students achieve learning results? The fourth and fifth points are "how to effectively know the learning results achieved by students?" and "how to ensure that students effectively achieve these learning outcomes?". These two points reflect the follow-up evaluation and improvement. The above five points are integrated to form an ecosystem of continuous improvement and correction, so as to achieve better educational results. 


\subsection{Research Route Design}

Taking the professional core quality of our students as the main research object, combined with the investigation of 36 schools at home and abroad, based on the OBE achievement oriented teaching concept, clarify the objectives and needs, take the economic statistics major of our university as an example, reform the curriculum system and talent training scheme, and build the professional core quality framework system of private undergraduate colleges, so as to enable students to form the ability to match the core quality, Then, an index evaluation system is established for capacity measurement to further guide the curriculum construction and training program. The research and design process is shown in Figure 1.

\subsection{Main Content}

\section{1) Analysis on the Characteristics of Core Literacy}

First, study the relevant conference contents and various research reports of "comprehensively promoting the construction of new liberal arts", analyze the relationship between the three modules of Chinese students' core literacy "cultural foundation, independent development and social participation" and the six elements "humanistic heritage, scientific spirit, learning to learn, healthy life, responsibility and practical innovation", as well as the internal relationship and logical relationship with the 18 key points, By collecting and sorting out the speeches made by the president at the opening ceremony of each university in recent three years and the development of starting education of each specialty, this paper studies the literacy prospect, academic prospect and employment prospect of students in the new liberal arts era, and analyzes the characteristics and keywords of core literacy and professional core literacy in combination with the data analysis results of China HowNet, The key words of private undergraduate students' professional core literacy are extracted, mainly focusing on "political literacy", "cultural literacy", "innovation and entrepreneurship literacy", "communication ability" and "professional application ability". Colleges and universities that prefer foreign language teaching also focus on the cultivation of "cross-cultural communication ability". Under the background of the new liberal arts, Chinese universities pay more attention to the penetration of domestic traditional culture, the development of interdisciplinary and cross-cultural integration and the application of the latest big data. The construction of professional core literacy of students in most private undergraduate universities is reflected in the theoretical framework system of level 3 indicators. Generally, the primary indicators are "political morality", "cultural exchange", "innovation and entrepreneurship" and "professional application", and the corresponding secondary indicators are subdivided into "political position, sensitivity", "cultural knowledge exchange", "competitive entrepreneurial ability", "professional application and social development", then, according to different professional characteristics, further refine the specific three-level indicators, and finally form a relatively complete professional core literacy training system. 


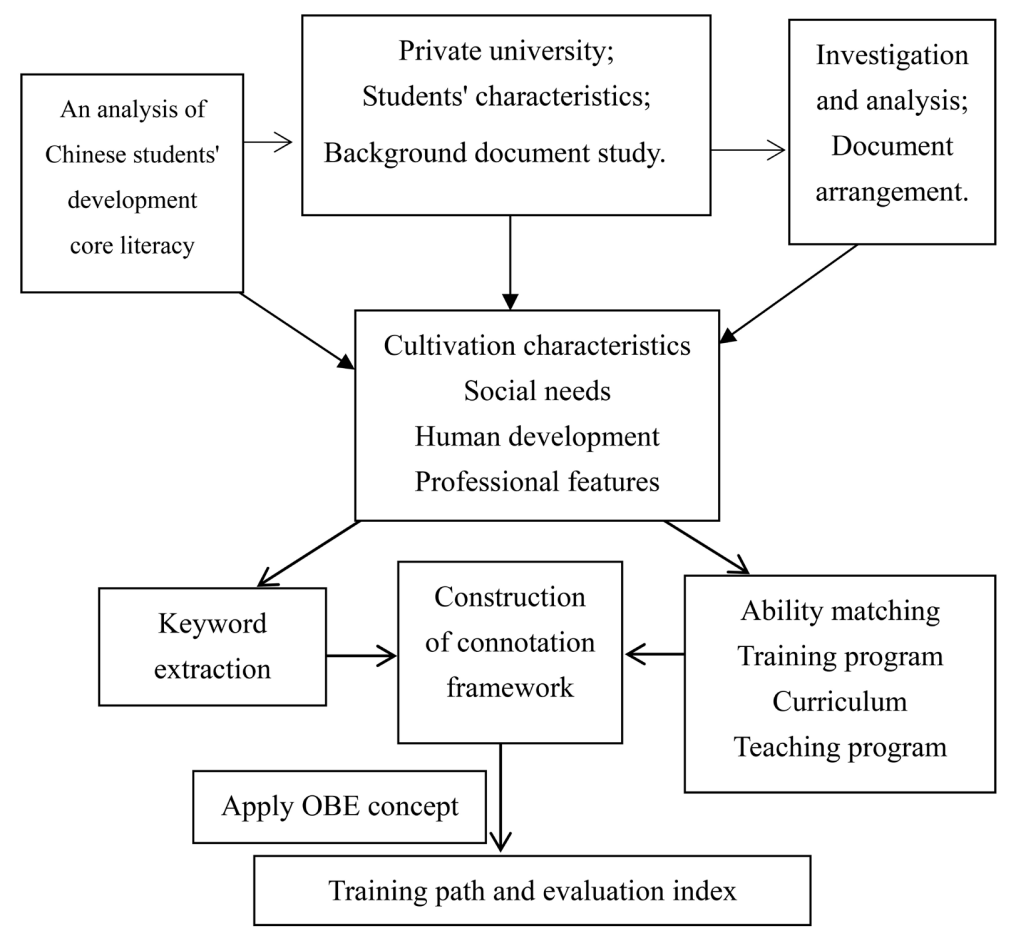

Figure 1. Research design flow chart.

2) Construction of training path of core literacy matching ability of Economic Statistics Specialty

As a new major in this foreign language college, economic statistics is an interdisciplinary subject of economics and statistics. The basic length of schooling is 4 years. The goal of this major is to collect and analyze economic data and solve economic problems with statistical methods. Drawing on the experience at home and abroad, referring to the school running ideas of Xiamen University, Shanghai University of Finance and economics, Jiangxi University of Finance and economics, Zhejiang University of Finance and economics and some private universities, combined with the foreign language plus characteristics of the University, the author constructs the path framework for the cultivation of core literacy of economic statistics, as shown in Figure 2.

In the first part of the "basic knowledge" module, the courses offered for political and moral quality are excellent traditional Chinese culture, College Chinese, family and country feelings and value ideals, four ideological and political courses, situation and policy and military theory. This part of the course focuses on cultivating students' political sensitivity and family and country feelings; In terms of cross-cultural communication literacy, the corresponding courses are comprehensive English 1 to 4, English listening 1 to 4, oral English 1 to 4 and English translation, business English, cross-cultural communication English and small language elective courses. This part focuses on highlighting the foreign language teaching characteristics of the University and cultivating students' international competitiveness; In the discipline foundation section, the courses offered are calculus, linear algebra, probability theory and mathematical statistics, 


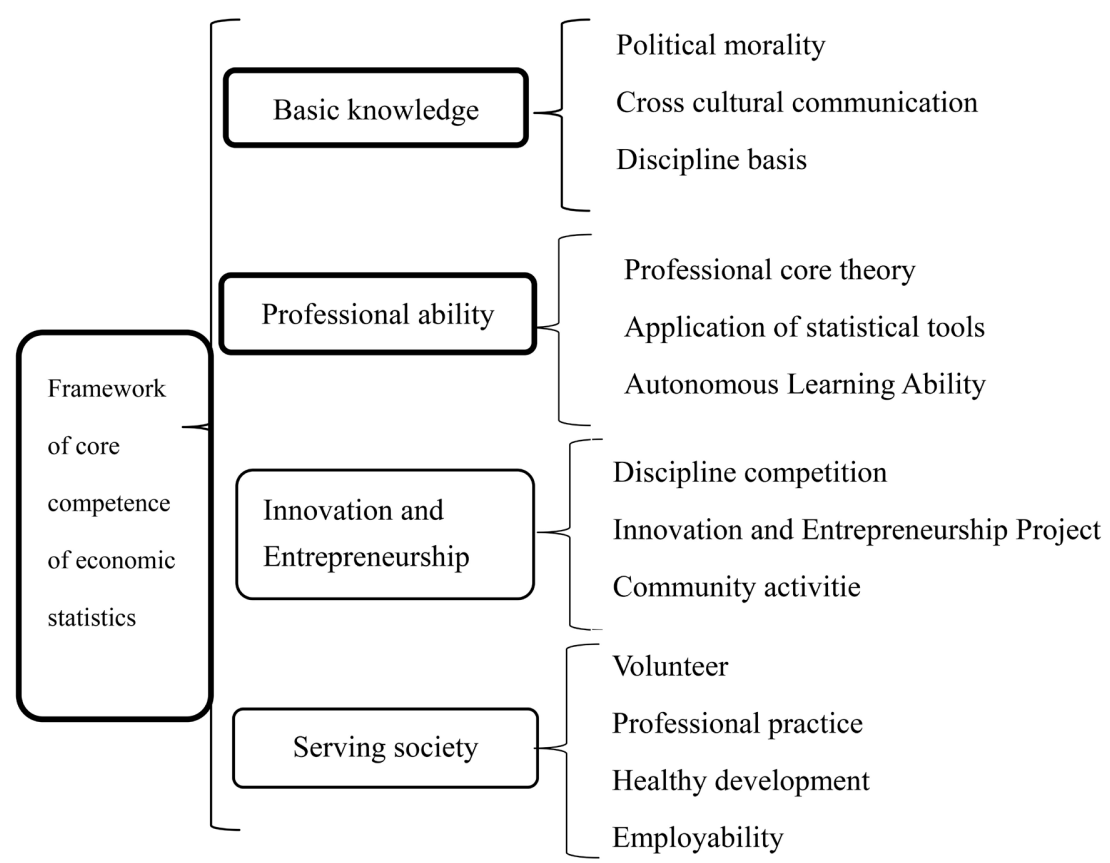

Figure 2. Training path of core literacy matching ability of Economic Statistics Specialty.

fundamentals of university computer, statistics, finance and accounting. This part focuses on consolidating the foundation of professional culture. In the second part of "professional ability" literacy, corresponding to the professional core, courses of microeconomics, macroeconomics, econometrics, finance, enterprise management economics, market research and prediction, time series analysis, national economic statistics and professional elective courses are offered; set up software application and experimental courses such as MATLAB, SPSS, R language and Python for the application of statistical tools; the part of autonomous learning ability can be called experimental operation, professional training and professional development, literature retrieval, etc. This part focuses on cultivating students' professional quality and autonomous learning ability.

The third part of "innovation and entrepreneurship" belongs to quality development. The courses are economic investigation training, statistical investigation training, economic data collection training, mathematical modeling training, comprehensive economic statistics training and special lectures, focusing on cultivating students' innovation and entrepreneurship practice ability. The fourth part is "serving the society" literacy, which involves courses such as community volunteers, professional practice, graduation practice, graduation thesis, sports, mental health, art appreciation, management, safety prevention, unity and cooperation and employability. It focuses on cultivating students to clarify professional responsibilities and make career planning, Have a sound personality, enhance people's all-round development ability and improve their ability to adapt to the society.

This training path refers to the provisions on professional curriculum in the 
latest edition of the national standard. Based on the OBE education concept, it optimizes the curriculum based on the ability to complete the matching of professional core literacy. Based on the idea of factor analysis, it tries to ensure the independence of level 1 to level 3. The last level is the curriculum matching corresponding to professional core literacy, we will establish personal electronic archives of academic achievements and achievements related to professional core literacy for comprehensive evaluation in the later stage.

\section{Construction of Evaluation System for Matching Ability of Professional Core Literacy}

Referring to the requirements of the new national standard for all majors in the university under the background of the new liberal arts, as well as the talent training scheme and the assessment system for students in our university, we use the improved fuzzy comprehensive evaluation method to establish a mathematical model to realize the evaluation of the professional core literacy matching ability system shown in Figure 2.

\subsection{Fuzzy Comprehensive Evaluation Method (Si, 2021)}

Fuzzy comprehensive evaluation method is a comprehensive evaluation method based on fuzzy mathematics. It transforms qualitative evaluation into quantitative evaluation according to the membership theory of fuzzy mathematics, that is, it uses fuzzy mathematics to make an overall evaluation of things or objects restricted by many factors. Fuzzy comprehensive evaluation method is often used in personnel assessment. According to the different purpose, object and scope of assessment, it can be flexibly used, such as one-level fuzzy comprehensive evaluation, two-level and three-level or even multi-level. It mainly realizes the comprehensive evaluation of the objectives through the following five steps:

1) Determine the set of factors, i.e. primary indicators;

2) Determine the evaluation set, that is, whether the five level system or the nine level system is used as the evaluation result;

3) The weight of each factor is usually determined by weighted average method or public evaluation method, and the sum of the weights is 1;

4) Determine the fuzzy comprehensive evaluation matrix;

5) Make a comprehensive evaluation.

\subsection{Improvement and Implementation of Fuzzy Comprehensive Evaluation Method}

Combined with the actual situation of economic statistics specialty, we made the following improvements: the first two first level indicators in Figure 2 are mainly related to academic achievement, so we weighted and quantified the reference credits of subject achievement, and divided them into five grades according to "less than 60 points, $60-70,70-80,80-90$ and greater than or equal to 90 ", corresponding to the five evaluation results of "fail, pass, medium, good and 
excellent" respectively; Since the latter two first level indicators involve subject achievement, comprehensive performance and follow-up employment tracking, we use the sum of subject achievement weighted average method and public evaluation method, and then give the evaluation grade. We can get the fuzzy comprehensive evaluation matrix, and finally calculate the evaluation results.

Combined with the credits of each course of our school's talent training program, we set the weight of the first level index as $\mathrm{A}=[0.36,0.39,0.11,0.14]$, and the weight of the second level index as $\mathrm{A} 1=[0.28,0.31,0.41], \mathrm{A} 2=[0.37,0.19$, $0.44], \mathrm{A} 3=[0.35,0.35,0.30], \mathrm{A} 4=[0.18,0.37,0.27,0.18]$ respectively according to the correlation and importance of matching ability. Suppose that the fuzzy comprehensive evaluation matrix of a student is shown in the following table, in which each row of data, such as the first row, refers to the courses corresponding to political morality, $80 \%$ are excellent, $15 \%$ are good, and $5 \%$ are medium (Table 1).

According to the table, the comprehensive evaluation result of the student is calculated by MATLAB as B $=[0.357,0.377,0.178,0.072,0.016]$. According to the principle of maximum membership, the evaluation grade of the student is good.

Table 1. Evaluation form of matching ability of professional core literacy of the student.

\begin{tabular}{|c|c|c|c|c|c|c|}
\hline \multirow{2}{*}{ Primary index } & \multirow{2}{*}{ Primary index } & \multicolumn{5}{|c|}{ Evaluation score } \\
\hline & & excellent & good & medium & pass & fail \\
\hline \multirow{3}{*}{ Basic knowledge } & Political morality & 0.8 & 0.15 & 0.05 & 0 & 0 \\
\hline & Cross cultural communication & 0.2 & 0.6 & 0.1 & 0.1 & 0 \\
\hline & Discipline basis & 0.5 & 0.4 & 0.1 & 0 & 0 \\
\hline \multirow{3}{*}{ Personal ability } & Professional core theory & 0.3 & 0.5 & 0.15 & 0.05 & 0 \\
\hline & Application of statistical tools & 0.2 & 0.2 & 0.4 & 0.1 & 0.1 \\
\hline & Autonomous Learning Ability & 0.4 & 0.4 & 0.1 & 0.1 & 0 \\
\hline \multirow{3}{*}{$\begin{array}{l}\text { Innovation and } \\
\text { Entrepreneurship }\end{array}$} & Discipline competition & 0.1 & 0.3 & 0.5 & 0.1 & 0 \\
\hline & $\begin{array}{l}\text { Innovation and } \\
\text { Entrepreneurship Project }\end{array}$ & 0.2 & 0.3 & 0.3 & 0.1 & 0.1 \\
\hline & Community activities & 0.2 & 0.3 & 0.35 & 0.15 & 0 \\
\hline \multirow{4}{*}{ Serving society } & Volunteer & 0.3 & 0.4 & 0.2 & 0.1 & 0 \\
\hline & Professional practice & 0.1 & 0.4 & 0.3 & 0.1 & 0.1 \\
\hline & Healthy development & 0.2 & 0.3 & 0.4 & 0.1 & 0 \\
\hline & Employability & 0.6 & 0.2 & 0 & 0.2 & 0 \\
\hline
\end{tabular}

\section{Conclusion and Recommendation}

1) Starting from the aspects of public foundation, professional development 
and human development, this training path innovatively adds the literacy of "tool application" and "healthy development", so that the application of statistical software tools can implement the learning process of the whole professional course, and healthy cooperation runs through the whole growth stage of life. The cultivation of students' professional core quality needs long-term tracking and training. In the four-year learning process of the university, the establishment of students' electronic archives based on data analysis can be effectively tracked.

2) After the matching of professional core literacy with the curriculum framework is completed, it needs to be clarified in the curriculum syllabus and the overall talent training plan, so as to provide an outline guarantee for further improving the matching ability of students' professional core literacy. The curriculum may be subject to the overall regulation of the education department and the school. At this time, it is necessary to further optimize the matching relationship between the curriculum and core literacy and modify some weight indexes.

3) When guiding the training path of core literacy matching ability based on OBE concept and evaluation system subsequently, we should pay special attention to the objectivity of expert subjective evaluation and the sensitivity of individual weighting in the index evaluation system, and appropriately update the curriculum system and evaluation system according to the index evaluation results and the tracking of students, in order to further optimize the training path and improve the talent training system.

\section{Funding}

This paper is supported by the educational science planning project of Zhejiang Province, "Research on the training path of private undergraduate students' professional core literacy matching ability under the background of new liberal arts" (Project No. 2021SCG363).

\section{Conflicts of Interest}

The author declares no conflicts of interest regarding the publication of this paper.

\section{References}

Duan, Y., \& Cui, Y. (2020). Theoretical Connotation and Practical Direction of New Liberal Arts Construction. Journal of Yunnan Normal University (Philosophy and Social Sciences Edition), No. 2, 149-156.

Fan, L. X. (2020). Analysis on the Cultivation of Core Literacy of Art College Students from the Perspective of Ideological and Political Education. Comparative Research on Cultural Innovation, No. 4, 113-115.

Liu, Y., Di, Z. P., \& Li, S. M. (2020). Research on the Training Mode of "Three Three System" Applied Talents Based on OBE. Journal of Higher Education, No. 32, 173-176.

Si, S. K., \& Sun, Z. L. (2021). Mathematical Modeling and Application (2nd ed., p. 375). National Defense Industry Press. 
Voogt, J., \& Roblin, N. P. (2012). A Comparative Analysis of International Frameworks for 21st Century Competences. Implications for National Curriculum Policies, 44, 299-321. https://doi.org/10.1080/00220272.2012.668938

Wang, L. F., \& Jin Y. J. (2019). Interpretation of Business English Teachers' Professional Core Competence under the Guidance of National Standard. Foreign Language Audio-Visual Teaching, No. 4, 61-66.

Xin, T., Jiang, Y. et al. (2016). On the Connotation Characteristics and Framework Positioning of Students' Development Core Literacy. Chinese Journal of Education, No. 6, 3-7.

Xu, G. X., Wei, R., Liu, J., Li, J. Y., Kang, C. P., Ma, L. H., Gan, Q. L., \& Liu, Y. (2020). Cooperative Literacy: The Fifth of the $5 \mathrm{C}$ Model of Core Literacy in the 21st Century. Journal of East China Normal University (Educational Science Edition), No. 3, 83-96.

Zeng, L. H. (2019). Essential Characteristics and Realization Path of Students' Sound Personality from the Perspective of Core Literacy. Journal of Wuyi University, No. 1, 100-104.

Zhang, H. (2016). On the Connotation of Core Literacy. Global Education Outlook, No. 4, 10-24. 